\title{
Aproximación al imaginario religioso del periodo independentista
}

\section{Por Fernando Muñoz}

\section{Resumen:}

El artículo pretende acercarse al imaginario religioso popular durante el periodo de la Independencia, como una propuesta de investigación sobre los sermones y como un esfuerzo por esbozar una historia de las ideas religiosas, realizando un análisis de los sermones pronunciados por el sector del clero eclesiástico que apoyaba la causa patriota. Se parte del presupuesto que el discurso religioso se llena de unas funciones de importancia considerable en las coyunturas históricas, de las que se destaca su función como cuerpo epistémico, es decir que interpreta la realidad del individuo, y su función coaccionadora, o sea que motiva al mismo a actuar decisivamente frente a esa realidad. El valor de los sermones en el análisis del imaginario popular, se basa en la fuerte influencia que tenía la Iglesia sobre su mentalidad, después de un largo periodo de evangelización durante el régimen colonial. Claro está, no se puede dejar a un lado la función de los sujetos como interpretadores del discurso y no como simples receptores pasivos del mismo, sin embargo este aspecto no está al alcance de este escrito, y hace parte de la investigación propuesta.

Palabras claves: Imaginario-sermón-iglesia-independencia

\begin{abstract}
:
This article pretends to make an approach to the popular religious imaginary during the period of Independence, as a searching proposal about sermons and as an effort to sketch a history of the religious ideas, analyzing the sermons pronounced by the sector of the ecclesiastical clergy, which supported the patriotic cause. The article starts from the assumption that the religious discourse gets some functions very important in every historical juncture, they are the epistemic function, which refers the interpretation that it gives to the reality of the individuals, and the co-action function, which refers the motivation that it gives them to act. The value of the sermons in the analysis of the popular imaginary is based on the big influence of the church in the mentality of people after a long period of evangelizing during the colonial regime. Of course, it is impossible to ignore the function of the subjects as interpreters of the speeches and not only as passive receptors of them; however this aspect is not treated in this work, but that is part of the searching proposal.
\end{abstract}

Key words: Imaginary-sermon-church-independence Introducción

En el proceso de independencia la Iglesia jugó un papel decisivo, sobre todo en lo que tiene que ver en la conformación y la difusión del discurso político religioso. El imaginario religioso de la época se vio "transformado" o reorientado, a partir de la interpretación que la Iglesia le dio a las circunstancias

\footnotetext{
* Artículo Tipo 2 según Colciencias. Artículo realizado para el concurso de ensayos de Bicentenario de la Independencia realizado por el Departamento de Historia de la Universidad del Valle.

${ }^{* * *}$ Licenciado en Historia de la Universidad del Valle. Estudiante de la Cuarta Cohorte de la Maestría en Historia de La Universidad del Valle.2010. Correo: fermusanz@yahoo.es.
} 
políticas del momento, mediante el uso de las imágenes sagradas en los sermones. Dicha transformación del imaginario y la recepción del discurso político por las masas populares conllevaron en gran medida al desarrollo ya conocido de los hechos de la Independencia.

La división del clero en dos bandos, por un lado el clero que apoyaba la insurrección emancipadora y por otro lado el que continuaba siendo leal al rey, hizo que aparecieran dos tipos de discurso: uno patriota y otro realista. Gran parte de las obras que estudian el asunto a nivel latinoamericano dan por sentado que del lado realista estaba el alto clero, obispos y arzobispos que por lo general eran españoles, y del lado patriota estaba el bajo clero conformado por presbíteros y monjes americanos. Sin embargo, resulta interesante la anotación que hace la historiadora Rosa María Martínez a este respecto enfatizando en los cambios de posición ideológica del clero en general y en la complejidad de estos cambios. Para ella, la confusión y el caos que reinó en las relaciones con España hizo que "la jerarquía eclesiástica [navegara], al igual que el pueblo, según los vaivenes de la revolución" (Martínez, 1992, p. 63), y después de su análisis, concluye: "Cuando los lazos con Madrid se aflojan entre 1808 y 1814 y entre 1820 y 1823, la mayoría de los obispos adoptan una posición neutral, inclinándose tímida o francamente a favor de la Independencia, entendida como el menor de los males o como la liberación de un poder impío o ilegítimo. Cuando los lazos con España se estrechan (1814 1820), la mayoría de los obispos y la cabeza de la Iglesia toman abiertamente posición contra la insurrección" (Martínez, 1992, p. 67). Por lo tanto más que a una división definida y definitiva entre el clero, Martínez apunta a la existencia de un clero que adapta su discurso a las circunstancias políticas, interpretando la realidad con los elementos sagrados.

La religión como forma de conocimiento brinda una interpretación a la realidad circundante y mueve hacia la acción a los adeptos, lo que no era desconocido por los actores del conflicto de la Independencia. De ahí que tanto patriotas como realistas vieron la religión desde una perspectiva funcionalista, dicho de otra manera como la forma de influir en las masas populares, para buscar apoyo a intereses propios.

Sobre el papel de la Iglesia en la Independencia se han escrito diversos textos que matizan el tópico de diferentes formas. Antes de comenzar nuestro análisis del imaginario religioso, realicemos una pertinente mirada panorámica de tales textos, seguido de una reseña breve de la importancia del sermón para la construcción del imaginario religioso.

\section{La Iglesia en la independencia, repaso bibliográfico.}

Comencemos por la clásica Historia Extensa de Colombia de 1970, que dedica un tomo a la Historia Eclesiástica. En la parte que corresponde al periodo independentista, su autor, Roberto Tisnés, expone varios casos particulares de clérigos y describe sus hazañas. Por ejemplo en el capitulo diez, titulado "La Independencia en la oratoria sagrada" (Tisne's, 1971), resalta la actuación del Cura Rector y Vicario Eclesiástico de Mompós, Juan Fernández de Sotomayor, a quien incluye entre los "campeones de la libertad" y realiza un análisis del discurso que tuvo lugar en el quinto aniversario de la Independencia, en el 
Congreso de las Provincias Unidas, discurso al que llama "Oración congratulatoria". En el capitulo diez nos habla del papel de las novenas, esta vez en las voces de un par de curas, el uno realista y el otro patriota. Las novenas eran, en palabras del autor, un "popular y eficacísimo vehículo de propaganda popular" (Tisne's, 1971, p. 530). Así, mientras que el presbítero Mariano Mendoza Bueno y Fontal las usó para defender la lealtad realista y para llamar a los patriotas masones y luteranos, su homólogo Pablo Francisco Plata denunciaba los abusos españoles en su titulada Novena en memoria y obsequio de los Dolores de la Santísima Virgen María Nuestra Señora de 1816, en la que al mismo tiempo imploraba por la libertad "espiritual del poder de los enemigos de [sus] almas, y en lo temporal del yugo de los tiranos de la tierra" (Tisne's, 1971, p. 533). Sobra decir que esta obra es una de aquellas historias patrias, cargadas de descripciones iconográficas y de conceptos heroicos, propias del momento.

Con el mismo objetivo de detallar y enaltecer los actos pro-libertarios de diferentes religiosos se escribió El capítulo metropolitano de Santa Fe y el grito de Independencia (Camargo, 1958). Su autor, Pedro Pablo Camargo de la Torre, afirmó: "No hay que olvidar que en cada batallón iba, por lo menos un capellán alentando a las tropas con las palabras del Divino Maestro, con el ejemplo de su abnegación, de su valor, y con la exaltación de la causa justa; en otros términos, cooperando en la medida de sus fuerzas al triunfo de las armas, como en los tiempos de paz habían cooperado en la difusión de la cultura y las verdades evangélicas en las cátedras y en el apostolado" (Camargo, 1958, p. 24). Estas palabras nos permiten anotar que la participación del clero dentro del ejercito, se centró en el manejo del discurso, o sea en la creación de la ideología religioso patriótica, cargada de fervorosos conceptos piadosos, tal como sigue por ejemplo: "[el sacerdote en] el cumplimiento del sagrado deber, le hace acompañar al soldado en la lucha, llevar la palabra de coraje y aliento al herido, curar las heridas corporales, mostrar al moribundo el camino de la gloria, de la verdadera gloria, la cual como un anticipo, el iba a alcanzar en la lucha; debe mostrar al soldado que lucha por la gloria y el triunfo" (Camargo, 1958, p.16). A diferencia de México en la que algunos clérigos lideraron la revolución independentista, en la Nueva Granada el clero patriótico se dedicó principalmente a formar una mentalidad patriótica popular ${ }^{1}$. A partir del capítulo tres, Camargo de la Torre se dedica a comentar la vida y las hazañas de los clérigos de Santa Fe en pro del ideal patriótico.

Algunas obras también clásicas, nos dejan ver el asunto de una manera más generalizada y no centrándose en personajes específicos. Tal es el caso del tomo tres de la Historia sagrada de la Iglesia en América Latina (Tormo y Gonzalbo, 1960), editada en 1961 y el artículo del Presbítero Rafael Gómez Hoyos titulado La Iglesia Granadina y la Santa Sede ante la Revolución de Independencia que hace parte de Grito de Independencia en Colombia de 1960.

\footnotetext{
${ }^{1}$ Ejemplos de curas que dirigieron los grupos insurgentes en: Gómez Alvares, Cristina. La Iglesia Católica y la Independencia Mexicana. En sitio Internet: .En el caso de México, el análisis del imaginario popular independentista no puede pasar por alto el trabajo de Erick Van Young. Sobre este se puede ver: Glave, Luis Miguel. Las otras rebeliones: Cultura Popular e Independencias. Anuario de Estudios Americanos, 62.1. Enero-junio 275-312, Sevilla, España. 2005. En sitio Internet:
} 
La primera de ellas, el tomo tres, titulado La Iglesia en la crisis de la Independencia, realiza un estudio general del papel de la Iglesia en cada uno de los países de América Latina. Cuando alude al caso colombiano, el texto expone datos sobre el comportamiento de diferentes instituciones eclesiásticas, sobre todo del clero de Santa Fe. Dice por ejemplo: "En Santa Fe tuvo una intervención muy especial en la revolución de julio de 1810 la parte más principal del clero, sobresaliendo varios distinguidos eclesiásticos. Entre los vocales de la Junta Suprema figuraron tres miembros del capítulo metropolitano y varios presbíteros" (Tormo y Gonzalbo, 1960, p. 47). El texto también nos comenta las vicisitudes que enfrentó el clero a medida que se establecía el nuevo gobierno, sus inquietudes por el liberalismo que a veces se asomaba en las posturas de personajes influyentes como Francisco Miranda y Simón Bolívar, las luchas por el respeto a la religión, la forma en que el clero realista utilizó la excomunión y las condenas para evitar el apoyo a la causa republicana, y las obras pacificadoras que llevó a cabo este mismo sector al ver el inminente triunfo de la República. El texto hace un seguimiento cronológico a cada uno de los sucesos de la revolución.

Por otro lado el presbítero Rafael López describe como fueron las relaciones entre la Iglesia americana neogranadina y la sede papal durante la revolución y los primeros años de Independencia. Sin embargo su texto retrocede hasta el periodo colonial y analiza con voz crítica el llamado Patronato Regio Indiano, acuerdo este, en el que el Papa otorgó al rey de España ciertos derechos y privilegios sobre la administración espiritual de las colonias y que resultó en la interrupción de la comunicación directa entre el clero neogranadino y la sede papal. La relación Iglesia-Estado que surgió en la Colonia, sería el modelo que perduraría hasta los primeros años del gobierno republicano. López nos expone las formas como, al pasar del tiempo, se establecieron las comunicaciones con la sede Papal y por ende, cómo fue la relación CleroEstado en los primeros años de Independencia.

En los textos anteriores se nota una gran exaltación del papel del clero patriota, dejando a un lado la actuación del clero realista. En este sentido, el volumen dos de la Nueva Historia de Colombia en su capítulo Estado, Iglesia y desamortización, nos permite ver, sin excesivos detalles, los distintos hechos llevados a cabo por el clero realista y el uso que este le dio al discurso por diferentes medios como sermones, cartas pastorales, volantes y documentos similares. Fernando Díez, su autor, escribe: "En tales escritos sale a relucir plenamente la ideología de la dominación, manifestada en la fidelidad al soberano español, la defensa del orden colonial, la conjunción de intereses entre monarquía y religión, como también en impugnaciones a la filosofía ilustrada, a la ingratitud de los criollos y a la supuesta igualdad entre los hombres, que planteaban los liberales" (1980). La encíclica Etsi longissimo del Papa Pío VII en 1816, se sumó a la causa realista, hablando de forma agresiva hacia la revolución. Posteriormente la encíclica Etsi lam Diu del papa León XII de 1824 reiteraría la postura realista del clero romano, al condenar la "cizaña de la rebelión". Sin embargo, no sería este el discurso que influiría en las masas populares, Díez afirma que la sede papal sobreestimó su influencia sobre los americanos, pero la realidad era que el discurso religioso patriota, 
mayormente atractivo, en contra del régimen colonial, pasaría por alto toda jerarquía, incluyendo la autoridad del Papa.

Algunas otras obras que nos amplían el tema de la posición de la sede papal frente a la Independencia y su actuación son Las relaciones entre la Santa Sede y Colombia de Germán Cavelier (1988) que trata las encíclicas legitimistas, narra en general los sucesos que llevaron a la sede papal a restablecer las comunicaciones con los obispos americanos y expone los efectos de este proceder; y Actitud de la Santa Sede ante la revolución de la Independencia, que corresponde a un capítulo del libro La Iglesia Católica en la América Independiente-Siglo XIX (Martínez, 1992), de Rosa Martínez, nos amplia el tema de las dificultades que afrontó el clero americano para comunicarse con el Papa y la reacción de este frente a la coyuntura política de América.

El capítulo tres de la obra de Martínez titulado La Iglesia Americana y su participación en las guerras de Independencia, se divide en subtemas que corresponden cada uno a la exposición de los hechos del clero en cada zona de los territorios coloniales españoles. Al exponer sobre el clero granadino, recuerda la gran influencia que este ejercía desde la colonia en las masas populares y por tanto, el poder que en ella vieron tanto las élites realistas como patriotas para animar a la acción a sus partidarios. La religión entonces se instrumentalizó y fue usada como "principio de orden y cohesión social". Algunos clérigos se sumaron a los ejércitos independentistas como capellanes o como soldados activos, otros "a través de seminarios, cartas pastorales, documentos varios, etc., llevaron a cabo la legitimación moral de la Independencia". Por otro lado, "La ideología del clero realista fue expresada mediante sermonarios, novenas discursos y folletos varios elaborados por curas y frailes. En tales escritos se refleja la ideología de la dominación manifestada en la fidelidad al soberano, la defensa del orden colonial, la conjunción de intereses entre monarquía y religión, así como en impugnaciones a la filosofía ilustrada .En general se consideraba que la Independencia atacaba la estabilidad de la religión y comprometía su futuro, motivos por los cuales la monarquía debía ser defendida. Por estas razones, la jerarquía eclesiástica recomendaba al clero secular y regular impulsar la fidelidad al rey desde el pulpito, en el confesionario o desde las páginas de un periódico" (Martínez, 1992, p. 93). La preocupación de los dirigentes de ambos bandos se deja ver en cartas en las que hacen alusión al peligro de los sacerdotes revolucionarios que como escribió Nariño, "todo lo quieren saber y gobernar" (Martínez, 1992, p. 94).

Actualmente se han publicado también diferentes artículos en revistas académicas disponibles también en Internet, sobre la Iglesia en el periodo Independentista. Es el caso de Clero insurgente y clero realista en la Revolución colombiana de la Independencia (2009) de Iván Darío Toro, texto que señala de entrada, la importancia de conocer el influjo de diferentes teologías en la formación y en la actuación de los clérigos de la época. La escolástica y el pensamiento de diferentes teólogos españoles pertenecientes a dicha corriente, impartidos desde los grandes centros de estudio en América, servirían como base retórica para los discursos religiosos insurgentes y 
fidelistas. En el texto encontramos buena cantidad de referencias bibliográficas sobre las formas de difusión de tales ideas. El texto finaliza exponiendo la obra proindependentista de cinco eclesiásticos: Francisco Padilla, Fernando Caycedo y Flórez, Juan Fernández de Sotomayor y Picón, Rafael Lasso de la Vega y Salvador Jiménez Padilla Cobos de Enciso, entre otros que estuvieron comprometidos con la causa revolucionaria.

Otro artículo es La religión católica en las constituciones neogranadinas de 1811 a 1815, de la abogada Erika María Velásquez. Este texto corresponde a una investigación sobre la cultura jurídica en el siglo XIX, que nos muestra el influjo de la iglesia en las diferentes constituciones emitidas en el periodo independentista. Pese a las ideas revolucionarias, la iglesia, que participó activamente en la coyuntura política, no se quedó por fuera de las nuevas legislaciones. Afirma la autora: "El catolicismo siguió teniendo, con carácter de exclusividad, una estrecha relación con la organización política y jurídica de las provincias, todo ello con el fin de mantener el orden a favor de los intereses del nuevo gobierno" (VElasquez, 2006, pp. 283-298). Por lo tanto también se pueden extractar elementos del imaginario religioso de las cartas constitucionales del momento. En estas, dios se convierte en un símbolo, se resalta el premio para los patriotas: el cielo, se resume el buen ciudadano en profesar la religión católica y se protege la religión como forma de conservar el orden social.

Este balance bibliográfico nos ha permitido dejar claro dos aspectos importantes para nuestro análisis. En primera instancia, que la Iglesia participó de forma decisiva y activa en el desarrollo del proceso que concluiría en la Independencia. Así, Jorge Tadeo Lozano presidente de Cundinamarca, en 1813 afirmó: "En una palabra, hasta la más remota posteridad se recordará [...] que la revolución que nos emancipó fue una revolución clerical" (Toro, 2009, p. 122). Y en segunda instancia, que su papel consistió básicamente en la construcción de un discurso ideológico político, ya fuese a favor del realismo, o a favor del patriotismo que fue el que finalmente venció. El secretario del Interior de 1850 escribió al Congreso: "El clero en nuestra patria gallardamente apoyó el grito de la Independencia, trabajando desde la cátedra de la verdad en difundir los dogmas luminosos de la libertad, fraternidad e igualdad y selló su consagración a la causa americana con inauditos sacrificios" (Toro, 2009, p. 124). La construcción del discurso político transformaría o modificaría el imaginario religioso social, y el medio para difundirlo sería el sermón. Pasemos entonces a detallar algunas características del sermón y la razón por la que fue tan eficaz en la manipulación del imaginario.

\section{El sermón en el siglo XIX}

Tanto en el siglo XIX como durante toda la Edad Moderna, el sermón fue un medio de difundir y fortalecer la fe católica, fue el instrumento predilecto en la predicación de la Iglesia y su poder no fue para nada desdeñable, pues se ha considerado que "fue una de las formas más directas de influir en la mentalidad popular" (Fernández, Marín y Rosado, 1983, p. 34).

Durante el siglo XVIII el sermón y la oratoria sagrada en general había sufrido en España una reforma motivada primordialmente por la poca seriedad y 
extravagancia en que habían caído algunos oradores. Como consecuencia de esto se hicieron muy comunes las críticas a la oratoria y los manuales que retornaban a la retórica clásica. Veamos las características que en criterio de los maestros de oratoria de la época, debía tener un buen sermón.

Los diferentes autores concordaban en que la tarea de pronunciar un sermón era un "empleo santo", y por esa razón, el predicador debía apegarse o ceñirse al texto sagrado, la Biblia. Como afirma Ricardo Sáez, "el sermón formaba parte de de una experiencia más que de un saber, de un encuentro con la letra viva de la palabra de Dios" (2002, pp. 46-61). Para que se convirtiera en una experiencia sagrada, el orador debía sentir lo que decía, es decir el contenido del sermón debía provenir del asiento de sus emociones. Esta combinación de palabra sacra y sentimiento, encausarían lo que se decía "al control de las ideas y reacciones del cuerpo social" (Saez, 2002, p. 50).

Se sumaban también a las características del buen sermón las referencias patrísticas, especialmente las de San Agustín, quien a comienzos de la Edad Media vio en al arte de la retórica un elemento "muy útil para la enseñanza de la fe por su elocuencia y capacidad de persuasión" (García, 2005, p. 3), solo aplicada en este campo la retórica era útil, de resto resultaba en mera vanidad. Sus objetivos, en ojos de este autor, solo se lograban de forma plena a través de enseñar y defender la doctrina cristiana considerada como verdad, y mover al pecador a la acción, al arrepentimiento. El atractivo del discurso dependía del tono y por lo tanto se debía "evitar el tono áspero y desagradable en los sermones" (García, 2005, p. 3).

Finalmente "el tema [del sermón] debía ser grave, sólido y educativo", y el que lo dirigía debía "saber llevar a los fieles hacia el amor de Dios, imprimir en los oyentes el odio al pecado, junto con un perfecto conocimiento de la naturaleza humana" (García, 2005, p. 37-40).

En resumen, siendo el sermón el instrumento de dios para persuadir, este debía estar ligado principalmente a la Sagrada Escritura, y a otros escritos eclesiásticos oficiales como los Concilios, debía acompañarse de la experiencia sacra de quien lo pronunciaba y debía apegarse a los principios retóricos enseñados por los padres de la Iglesia. Estas cualidades caracterizaron y al mismo tiempo fortalecieron los sermones del periodo independentista en la Nueva Granada. Para las masas populares, el sermón representó el medio por el cual dios se comunicaba con sus fieles. Lo que se decía desde el pulpito era lo que mandaba dios, y por lo tanto lo que se debía respetar, creer y hacer y esto estaba legitimado por el papel que por mucho tiempo, durante todo el periodo colonial, la Iglesia había desempeñado en la enseñanza y administración de la fe.

Por lo tanto, en las manos del clero de eclesiástico reposaba la construcción y orientación del imaginario religioso de la época, lo que este afirmaba tenía un poder basto en la gente. Pasemos ahora a ver la orientación que le dieron los sermones del clero al imaginario religioso para interpretar la realidad del momento e influir en la actitud y en las acciones de la gente. 


\section{El sermón independentista en Nueva Granada.}

Aunque los sermones eran pronunciados desde el pulpito en las misas, muchos se escribieron y se compilaron en los llamados sermonarios. Muchos sirvieron como modelo para los clérigos novatos o para aquellos que no tenían buenas capacidades en la oratoria. Los discursos religiosos patriotas que analizaremos reposan en el Archivo General de la Nación, serie de oratoria sagrada del fondo Enrique Ortega Ricaurte (AGN, Serie Oratoria Sagrada, 1735-1850); la mayoría de estos fueron escritos hacia 1819, momento en que ya en el horizonte se percibía el total triunfo de las tropas libertadoras.

\section{Interpretación de las circunstancias del momento}

Para una sociedad cuya actitud religiosa es inherente como el caso de la sociedad decimonónica de la Nueva Granada, el discurso religioso no solo cumple con la función de cubrir requerimientos espirituales de sus integrantes, sino que sirve como herramienta epistémica para interpretar la realidad, es decir las circunstancias históricas que les rodean. Estas circunstancias parecen estar sujetas al cambio constante y, de no estar bajo el dominio de lo sagrado, arrojarían a la humanidad al caos. Mircea Eliade, estudioso de la religión, afirmó que el hombre no pudiendo vivir en el caos, busca en lo sagrado y en su manifestación, un mundo significativo, un mundo que en primera instancia se pueda entender y posteriormente controlar (Eliade). Teniendo esto presente veamos las interpretaciones de la situación en los sermones.

Los tres siglos de la dominación española y también los tres años de avanzada de la llamada Pacificación por Pablo Morillo, no tenían otra explicación en el imaginario religioso, sino el pecado ${ }^{2}$. Esta idea la recoge muy bien el cura de Funza, Pedro José Almanza, cuando afirmó: "Y no creáis señores, que otra es la causa de nuestras aflixiones sino el pecado, el vicio y la iniquidad. Así nos lo dicen las Santas Escrituras, y lo que es más, el testimonio de nuestra conciencia nos arguye y convense" (AGN; Serie Oratoria Sagrada, fol. 25). Es la actitud relajada que han tenido los neogranadinos en cumplir con lo que dios manda, lo que en voz de los sacerdotes, causa las malas condiciones en que se estaban viviendo, el caos del que habla Eliade, cuando las cosas no están consagradas a lo divino. Como causa de este mal actuar, el cura de Turmequé afirmó que dios había castigado al pueblo neogranadino, permitiendo por ejemplo, la retoma de la ciudad de Santa Fe en 1816, dijo: "fue porque nos hallábamos desunidos, y por la justa indignación de dios por nuestros pecados , valiéndose de ellos el señor como de un asote para castigarnos" (AGN, Serie Oratoria Sagrada, fol. 55). La ira y el castigo divino por el pecado eran por tanto en el imaginario religioso los conceptos que explicaban el mal momento por el que pasaban los neogranadinos.

Naturalmente como aspecto primordial en los sermones, lo que se decía se apoyaba en relatos del texto sagrado. El ya referido Almanza aludió a los libros

\footnotetext{
${ }^{2}$ Para el católico el pecado es "Una falta contra la razón, la verdad, la conciencia recta; es faltar al amor verdadero para con Dios y para con el prójimo, a causa de un apego perverso a ciertos bienes. [...]” El pecado se levanta contra el amor de dios y aparta los corazones de él. Ver: Catecismo de la Iglesia Católica. Librería Juan Pablo II. Colombia, 1992. Tercera parte, primera sesión, capitulo 1, articulo 8, \# 1849 y 1850 . Págs. $416-417$.
} 
del pentateuco (de Génesis a Deuteronomio) para explicar el beneficio de la obediencia a dios como paz, larga vida, salud perfecta, abundancia y más, pero: "por el contrario que amenazas tan terribles hace [dios] a este pueblo [Israelita y por extensión al neogranadino] si por seguir el mundo de las pasiones, quebrantare sus mandamientos, y se entregase a la culpa. Si no oyeres, dice el señor, sino oyeres la voz del señor tu Dios vendrán sobre ti estas maldiciones: [...]" (AGN; Serie Oratoria Sagrada, fol. 25), maldiciones que se encuentran en el capítulo 28 del libro de Deuteronomio, a partir del versículo 15, y entre las que se encuentra la invasión, el sitio y el despojo de las ciudades del territorio propio por parte de naciones extranjeras enviadas por dios (versículos 49 - 52). El cura de Turmequé recuerda las aflicciones de Antíoco, rey griego hacia los judíos en tiempo de Matatías, registradas en la historia de los Macabeos y alude a títulos bíblicos como "señor de los ejércitos" para referirse a dios. En otros sermones se utilizan como ejemplos del castigo divino por pecado, las ciudades de Sodoma, Gomorra, Babel, y a personas como el rey babilonio Nabucodonosor, quien comenzó a actuar como una bestia, comiendo pasto, por profanar los objetos sagrados del templo de Jerusalén. En general en los sermones se usan muchas citas bíblicas de forma directa o indirecta, pues siendo esta considerada la Palabra de Dios y por lo tanto la Verdad, le concedía más peso y autoridad a lo que se explicaba desde el pulpito.

Pese a las condiciones difíciles de los neogranadinos, en voz de los sermones por causa primaria del pecado, las cosas podían cambiar ganando la gracia divina $^{3}$, pues, dijo el cura de Villeta: "Toda felicidad depende de la gracia de Dios". Esta gracia se lograría mediante cumplir los mandatos establecidos por dios pero también luchando contra el enemigo, asunto que ampliaremos posteriormente. De manera que aunque las circunstancias eran duras, estas se convertían en el imaginario religioso, en una magnífica oportunidad para mostrar cuanto amaban a dios y actuar a favor de la justicia divina, que como analizaremos a continuación se sintetizaba en la Independencia del pueblo neogranadino.

\section{Justificación de la Independencia: Revaluación del concepto de Herejía.}

La redirección del imaginario religioso, que fundamentalmente apoyaba el régimen tradicional, se convirtió en una tarea de esencial importancia en los sermones eclesiásticos patriotas. Los sermones realistas condenaban de Herejes a todas aquellas personas que simpatizaran o que apoyaran los proyectos en contra del rey ${ }^{4}$. La condena era fuerte si tomamos en cuenta que el Papa, autoridad máxima de la Iglesia se había pronunciado fuertemente en 1816, en documento oficial, en contra de los brotes de rebelión; y que según la doctrina, la paga de la desobediencia y la rebeldía con plena conciencia y

\footnotetext{
3 "La gracia es el favor el auxilio gratuito que Dios [...] da para responder a su llamada". Ver: Catecismo de la Iglesia Católica. Óp. Cit. Tercera parte, primera sesión, capitulo 3, articulo 2, \# 1996. Pág. 443.

4 "Se llama Herejía la negación pertinaz, después de recibido el bautismo, de una verdad que ha de creerse con fe divina y católica, o la duda pertinaz sobre la misma", esto se incluye entre los pecados contra la fe. Ver: Catecismo de la Iglesia Católica. Óp. Cit. Tercera parte, segunda sesión, capitulo 1, articulo 1, \# 2089. Pág. 464 y 465.
} 
entero conocimiento, es el castigo en tormento eterno ${ }^{5}$. De manera que los sermones patriotas tuvieron la tarea de, a la luz de la razón, de la teología y sobre todo de la Sagrada Escritura redimensionar el concepto de herejía, para eximir de las mencionadas condenas realistas, a quienes apoyaran la Independencia.

Veamos como desarrolló este objetivo el sermón del cura de Funza. Su discurso comenzaba recordando que la escrituras mandan a sujetarse a las potestades superiores, tal vez aludiendo al texto de Romanos 13:1 ${ }^{6}$. En este caso se refería a las potestades patriotas, que como el mismo aclaró fueron quienes mandaron a pronunciar su mensaje. Tal como interpretó las escrituras, estas autoridades estaban allí porque dios lo había permitido y por tanto eran legítimas en su regir, pues de hecho dios siempre ha querido que el hombre tenga un superior; entonces pasa a repasar y comentar los gobiernos de la historia bíblica desde Adán, a quien dios dio autoridad sobre todo lo que había hasta entonces. Por tanto la primera razón por la que no sería hereje una persona que apoyara la Independencia era que contrario a desobedecer deliberadamente los preceptos de la fe, obedece y está en sujeción a las potestades superiores tal como manda dios.

Como segunda razón el cura alude al hecho de que el mismo sistema patriota no se opone a la Iglesia. En palabras de nuestro personaje: "Dios ha querido poner en las manos de los hombres, la autoridad, el mando, el gobierno, y quiere que todos reconoscamos a un superior, que regule y ordene las operaciones de cada uno de los hombres. De esto es una prueba irrefragable primero: que el actual sistema de libertad, no se opone a la fe de Jesuchristo nuestro señor; y que así no son herejes los que le siguen" (AGN, Serie Oratoria Sagrada, fol. 24). Es decir, que si dios ha permitido la potestad de un gobierno patriota es porque esta es su voluntad, y prueba de ello es que este gobierno apoya a la institución eclesiástica y su doctrina de fe: "Pues si como he dicho solamente es hereje el que niega o se aparta en alguna parte de la fe de nuestro señor Jesuchristo; el que niega alguna cosa del dogma christiano; ¿Cómo calificaremos de Herejes a los que en asunto políticos siguen la vos común?" (AGN, Serie Oratoria Sagrada).

Y como tercera razón está, en que si bien ser hereje es negar un precepto de la fe católica, no hay ninguno de estos que señale como mandamiento someterse a un gobierno monárquico. No hay por lo tanto ningún documento oficial con que se pueda concluir que es hereje quien no apoye el gobierno español. Afirmó: "Hasta ahora la Iglesia nuestra madre que es la regla de la fe no ha declarado casa alguna en orden a la obediencia que deben tener los hombres al gobierno monarchico, que sea artículo de fe, ni tampoco ha condenado como opuesto a la fe el gobierno republicano".

\footnotetext{
${ }^{5}$ No está de más recordar que el análisis que estamos haciendo es del imaginario religioso y que por esta razón no hablamos del miedo a ser encarcelados, a morir fusilados, etc.

6 “Que cada uno se someta a las autoridades que están en el poder, porque no hay autoridad que no venga de Dios; y los que han sido puestos por Dios" En: La Biblia para el pueblo de Dios. Sociedad Bíblica Católica Internacional. Bogotá, 2008.
} 
Deshacerse de la nominación de herejes representaba un alivio para las conciencias de los creyentes católicos. Esto les daría ahora una luz verde a su participación activa en el proceso independentista. Sin embargo nos concentramos tan solo en el sermón del cura de Funza, pero aún podemos destacar más argumentos que justificarían el apoyo a la Independencia, como es el caso de la Ley Natural.

\section{Justificación de la Independencia: La Ley Natural}

En muchos de los sermones se hizo alusión al concepto tomista medieval de Ley Natural, concepto que se entiende como el conjunto de principios deducidos de la ley superior o Ley Eterna, es decir la ley de dios. Por debajo de esta ley, está la ley humana, que en ocasiones podría chocar con la naturaleza. Para Tomás de Aquino en estos casos, hay que priorizar el cumplimiento de la ley natural sobre la ley humana, que de hecho, debe ser violentada (Aquino, 1955, p. 146). Esta ley es comparada y hasta equivalente a la razón. En el sermón de Turmequé, el sacerdote se refiere esta, como la ley que está escrita y es indeleble en los corazones de los seres humanos, "esta ley no es otra cosa que la recta razón, que está impresa en [las] almas, para que regulando por ella todas [sus] operaciones obren el bien y huyan del mal" (A.G.N, Serie Oratoria Sagrada, fol. 52). Aquí notamos nuevamente el uso del texto bíblico, en esta ocasión apoyando la idea tomista de la Ley Natural en el texto bíblico de Romanos 2:15 .

Es sobre este concepto de Ley natural en el que soportarían los líderes religiosos de los que estamos hablando, las ideas que favorecen el patriotismo. La independencia desde este concepto no solo dejó de ser un plan hereje, sino que es totalmente racional, necesaria y hasta inevitable, pues es de hecho lo que quería dios y lo que mandaba a buscar. Así el gobierno español se convirtió en antinatural y por lo tanto ilegítimo. Esto último fue sustentado por el cura Luis Calvo en la historia bíblica. Sinteticemos a continuación su discurso.

El hombre fue creado por dios de forma libre e independiente, Adán y sus sucesores no tuvieron rey, ni otro superior sobre la tierra. Cansados de vivir errantes y solucionando sus diferencias de forma violenta, se reunieron en sociedades y decidieron crear un gobierno que les solventara sus desavenencias, ese fue el origen de los gobiernos. En este punto refiere al libro de Deuteronomio, donde dios manda a elegir un gobernante del propio pueblo, texto que Calvo utilizaría para sostener primero, que el pueblo es el que legitima el gobierno y segundo que este gobierno debe ser propio, no extranjero. Ninguna de las dos condiciones se cumplen en el caso del gobierno español y por lo tanto su conclusión fue: "no es legítima su autoridad y por consiguiente contra la Santidad Divina" (A.G.N, Serie Oratoria Sagrada, fol. 113).

La escuela de la naturaleza por lo tanto señala la Independencia como lo justo y lo racional. La libertad como uno de los mayores bienes que puede tener un

\footnotetext{
7 “...muestran que llevan la ley escrita en sus corazones, según lo atestiguan su conciencia y sus pensamientos, que unas veces los acusan y otras los defienden”. En: La Biblia para el pueblo de Dios. Sociedad Bíblica Católica Internacional. Bogotá, 2008.
} 
ser humano ha sido concedida como regalo por dios, desde el mismo principio (naturaleza) para que el hombre sea feliz. Pero esa libertad, y la felicidad que de esta resulta, no se pueden disfrutar sino hay Independencia. Así que la Independencia es un concepto inseparable de Libertad. El sermón de Umbita (A.G.N, Serie Oratoria Sagrada, fol. 118) es encabezado por el texto bíblico de Segunda a los Corintios 3:17, en el que se lee: "Donde está el espíritu del señor, allí hay libertad"8. Entonces como síntesis, la ecuación de lo que designaba en este caso la Ley Natural sería: presencia de dios, igual a Independencia, Independencia igual a Libertad.

Resulta interesante como se perciben filtraciones del pensamiento de la Ilustración en el discurso religioso. Ya percibíamos por ejemplo en las ideas del presbítero Luis Calvo atisbos de la doctrina del "contrato social"; influjos de John Locke y su tipo de Estado, creado por los humanos en consenso popular para que proteja los "derechos naturales" que son voluntad de dios. También en el presbítero de Umbita y su relación Libertad-Independencia, se avista a Rousseau con su teoría de Estado Protector de la Libertad definida como autodeterminación, o sea la posibilidad de decidir libremente, independientemente, si las decisiones individuales se orientan hacia el bien común o no. Es posible percibir en la deslegitimación retórica de la monarquía una orientación hacia cierta democracia-burguesa, por cierto en boga en la Europa del momento.

\section{La salvación y la participación en la Independencia.}

Si la Independencia era natural, era por lo tanto voluntad divina. La monarquía se convirtió en un estorbo para el libre fluir de la naturaleza, es decir para la voluntad de dios. Bien confirmo esto el cura de Turmequé cuando dijo: "Dios manda guardar y sostener la Religión sacrosanta: Dios manda obedecer a las potestades: Dios manda evitar cuanto sea perjudicial a la Patria; y siendo esos unos principios irrefragables e inmutables; dejareis entrar en nuestro suelo, a unos enemigos, que solo conspiran a quitarnos la vida, y a esclavizarnos?" (A.G.N., Serie Oratoria Sagrada, fol. 55). Las leyes de dios no se podían cumplir bajo el dominio extranjero, y el asunto se vuelve de autentica seriedad cuando se piensa en la salvación, pues si no se cumplía la voluntad divina desaparecía del horizonte la esperanza de la salvación. Por lo tanto la lucha por la independencia adquirió un matiz escatológico, en la que las fuerzas del bien forcejaban contra las fuerzas del mal por la salvación de la humanidad en un nuevo orden, de retorno a una edad de oro.

Notemos la confirmación de la idea de la salvación en las palabras de José Foribio García: "El negocio más importante es el de nuestra salvación, y esta se puede arriesgar si perdemos nuestro patrio suelo, prisioneros con grillos en los pies, arrastrando cadenas e impredecibles martirios si llegáramos a ser presa de nuestros enemigos; y teniendo a Dios de nuestra parte guardando unión , y concordia, nos hacemos inexpugnables, viviremos después con tranquilidad [...] y después legaremos en la patria celestial de la gloria . Amén." (A.G.N, Serie Pratoria Sagrada, fol. 77). Por lo tanto ser partidario de la

\footnotetext{
${ }^{8}$ La Biblia para el pueblo de Dios. Óp. Cit.
} 
independencia llegó a significar el comienzo, y a la vez requisito indispensable, de la salvación del individuo.

\section{Imágenes sagradas, el eterno retorno.}

El discurso religioso es en esencia un discurso esperanzador frente a la realidad que en ocasiones se torna caótica cuando se pierde el favor divino. La esperanza está orientada a la recuperación o la restauración de un "tiempo mejor", de una edad de oro, del illo tempore que menciona tantas veces Eliade en su extensa obra cuando estudia la nostalgia constante del homo religiosus por retornar al buen tiempo (Eliade, 1984). Para el católico, parte de nuestro objeto de estudio, el tiempo de las sagradas escrituras, es un tiempo sagrado, y los acontecimientos que allí tuvieron lugar se convierten en arquetipos o modelos que se repiten vez tras vez en tanto se siguen las formulas que los mismos relatos transmiten. Es por esa razón que se hace referencia tantas veces a dichos acontecimientos en los sermones. Tomemos por caso las citas de los Macabeos.

Narra el libro primero de los Macabeos las hazañas del sacerdote Matatías para lograr la Independencia del pueblo judío del yugo del rey Antíoco, cuyo general Apolonio saqueo y profanó el templo de Jerusalén. En un sermón de Guaduas se identificó a Pablo Morillo como el general del Antíoco de Europa, que entró con su ejército en supuesto son de paz y protección, pero una vez adentro de la Nueva Granada, todo se convirtió en caos, "empezaron las prisiones, los embargos, los suplicios y todo género de males", profanando tal como Apolonio profanó el templo de Jerusalén, las cosas sagradas de América. "Quebrantaron la disciplina de la Iglesia, quitando y poniendo curas sin jurisdicción. Robaron las alajas y basos de muchas iglesias, que el vicario mandó a hazer basos escretorios: de una potencia del Cristo de Ubaté algo variada, alfiler del pecho, del manto de la Virgen de los dolores Gualdrapa para su cavallo" (A.G.N., Serie Oratoria Sagrada, fol. 144). Con todo, la Independencia del pueblo judío llegó a feliz término, en voz del discurso, por la valentía y el proceder piadoso de Matatías y sus hijos. Esta era la clave que arrojaba el relato de aquellos tiempos: la Independencia de América se lograría por la imitación de los Macabeos, mostrando valentía y piedad. La vuelta al tiempo de gloria y júbilo del pueblo de dios, solo se lograría siguiendo los pasos que el relato sagrado, como si fuera una fórmula mágica, contenía.

\section{Mesianismo en la figura de Simón Bolívar}

Luces del fenómeno mesianista también se hicieron presente en el escenario decimonónico con la figura Simón Bolívar. La creencia en la aparición de un personaje libertador que lleva al pueblo a un nuevo orden o al retorno de los buenos tiempos, se ha hecho presente en toda la historia latinoamericana. Alicia Barabas, estudiosa del mesianismo y de los movimientos religiosos en México, dice que "el mesianismo constituye una dinamización de las creencias y de la acción, ya que la próxima llegada de un esperado emisario divino, que revela a los hombres el mensaje de la salvación, sienta las bases para la constitución de una nueva comunidad - la de 'los elegidos' - cuyas expectativas sacralmente legitimadas son totalizadoras (instaura próximamente en la tierra, la sociedad perfecta) por lo que suelen encaminar las acciones de la colectividad hacia la rebelión contra la realidad establecida" (Barabas, 1991, 
p. 19). De nuevo notamos el carácter legitimador del discurso religioso; en nuestro caso la legitimidad de Simón Bolívar como mesías que incita a la rebelión contra el orden establecido, sustentada en la profecía bíblica. Algunos de los sermones contenían este mensaje de forma directa, otros de forma implícita.

Un ejemplo de los sermones explícitos en este sentido fue el del cura de Guaduas. Notemos hasta qué punto confirma el carácter cuasi mesiánico de Bolívar. Dijo el presbítero, después de hablar de la independencia por los Macabeos: "Ay tenéis a Simón, él es vuestro hermano, sé que es hombre de consejo, dídlo y atendedlo siempre, el será vuestro Padre. Señores parece más bien esto una profecía de lo que había de suceder el año [...] que un suceso acaecido el año de la monarquía de los griegos" (A.G.N., Serie Oratoria Sagrada, fol. 133). Bolívar como "hermano", es decir como quien conoce el sentir del pueblo, pues hace parte de él y por lo tanto lucha por sus intereses; Bolívar como "Padre", quien protege, quien ama y a quien por su sabiduría se debe seguir y obedecer; y por encima de todo Bolívar como quien sigue el modelo de un libertador bíblico, y en quien parece cumplirse la profecía divina. Aún mas confirmado queda el asunto, con lo que dijo a continuación: "¡Bendito sea para siempre el benturoso instante en que la providencia dio a Colombia, a nuestro hermano Simón, que como el primer astro de este país, dicipa la densa nube de nuestros enemigos vibifica y anima todo con sus luces!" (A.G.N., Serie Oratoria Sagrada, fol. 134). Es de hecho voluntad de dios el que Bolívar sea el libertador de la Nueva Granada.

Otra referencia es la del sermón del presbítero García en Villeta. Para él Simón Bolívar es una respuesta de dios a los clamores del pueblo ante la retoma de la Nueva Granada por los españoles. Escuchémoslo: "[dios] que oyó nuestros clamores que vio nuestra aflicción, que escuchó nuestros lamentos, que atendió nuestras quejas, y al instante apareció nuestro General Bolívar y qual otro Moisés en Egipto que dio la libertad al pueblo escogido de Dios de la tiranía de Faraón, dio libertad a la Nueva Granada de la tiranía del español". Entonces, Bolívar se convirtió en el imaginario religioso de la época sino un enviado de dios, en un hombre especial, un hombre clave, a quien se le debía escuchar, pues se le vaticinaba como el libertador de la opresión de la corona y el restaurador de la adoración a dios.

\section{Llamado a la acción}

Hemos visto como desde el sermón, el discurso religioso ha dado una interpretación a los acontecimientos del periodo Independentista y de hecho ha justificado y legitimado con las escrituras sagradas y con la luz de la razón muchos de los actos prolibertarios. No hay duda entonces que se creó en la mente de los individuos no solo una fundamentación epistémica, sino ideológica que les permitiría ahora tomar partido en el conflicto, y aún más allá les impelería a actuar de forma activa. La motivación a la acción, es así una característica general en muchos casos del discurso religioso. Alicia Barabas afirma: "La cosmovisión religiosa opera como fundamento para la comprensión del mundo social, como germen de la rebelión y como guía para la acción colectiva" (Barabas, 1991, p. 19). Podemos clasificar en dos, las formas en que los sermones invitaron a actuar a los adeptos católicos, por un lado la forma 
ritual, que consistía en la rogativa y la veneración de los santos, lo que no es para nada una actitud pasiva si tomamos en cuenta lo que esto significa para el homo religiosus; y la forma bélica que consistía en tomar las armas e ir al frente de batalla.

En cuanto a la primera forma de actuación, veamos algunas citas. El cura de la Meza en su sermón alude a la circular enviada por el gobierno republicano a todos los curas para que se hagan rogativas a los santos patronos de cada ciudad y así obtener su favor en la batalla y en la dirección de la nueva república. Muchas son las referencias a la sabiduría de la virgen, por ejemplo el cura de Guaduas dijo: "Imploremos los auxilios de la Gracia saludando a María con el cántico de sus glorias. Ave María." (A.G.N., Serie Oratoria Sagrada, fol. 134). Y el cura de Villeta al comenzar su discurso solicitó: "A ti recurro o madre de piedades, dad auxilio a este suelo Americano, para que sus habitantes unánimes en la fe, constantes en la opinión, y fuertes en el obrar, se hagan inexpugnables" (A.G.N., Serie Oratoria Sagrada, fol. 117b).

Por otro lado, están las invitaciones a la acción en el frente de batalla, como las palabras directas del presbítero de Turmequé: "contando con la protección del todo poderoso deveis correr valerosamente al campo de la batalla a defender nuestras propiedades y la salud de la patria" (A.G.N., Serie Oratoria Sagrada, fol. 54), y después de este llamado les recuerda a cuantos habían muerto por la patria, todos ellos unos héroes, "cuya diversión estaba en las armas y su descanso en le pelear". Pero mucho más explícitas son las palabras del presbítero de Guaduas cuando aseveró: "Cómo es que no morimos al figurarnos que los Godos pueden volver algún día a dominarnos? ¡Ha! porque estamos resueltos a empuñar la lanza, y abrir con ella el pecho de nuestros asesinos; a morir primero en esta gloriosa lucha que sobrevivir a tanto horror" (A.G.N., Serie Oratoria Sagrada, fol. 138).

\section{Conclusión}

Aunque no hay duda que miembros del clero estuvieron en el frente de batalla, su participación significativa en la Independencia consistió en administrar lo sagrado. Mediante el sermón, herramienta práctica y eficaz de adoctrinamiento, el imaginario religioso de la época fue dirigido hacia la causa patriótica, explicándola, justificándola y poniéndola como la mejor opción para el pueblo neogranadino. Las imágenes sagradas como los santos, los héroes bíblicos, los Padres de la Iglesia Católica, la misma escritura, fueron usadas para sustentar la participación activa ya fuera orando a los santos y a María, pero también derramando sangre en el frente de batalla. El discurso religioso ofreció a los neogranadinos una esperanza de salida a las condiciones que les atormentaban, enfatizando en la imposibilidad de que el mal triunfara y poniendo a la voluntad de dios por encima de todo.

\section{Bibliografía}

\section{Fuentes Documentales}

Serie Oratoria Sagrada. (1735 - 1850). Fondo Enrique Ortega Ricaurte. Bogotá: Archivo General de la Nación.

\section{Fuentes bibliográficas}


Aquino, Tomás de. (1955). Summa Teológica. Nueva York: Thomas Gilby Ed. Nueva York, Oxford University Press.

Barabas, Alicia. (1991). "Movimientos Socio-religiosos y Ciencias Sociales". En El mesianismo contemporáneo en América Latina. Religiones Latinoamericanas, No 2.

Bethell, Leslie. (1991). Historia de América Latina. Tomo 5. Barcelona: Crítica.

Camargo de la Torre, Pedro Pablo. (1958). El Capitulo Metropolitano de Santa $\mathrm{Fe}$ y el Grito de Independencia. Bogotá: Pontificia Universidad Católica Javeriana.

Carreño Miryam. (2006). El despertar de la conciencia cívico política popular en los inicios de la España contemporánea: La politización de los sermones en la Guerra de la Independencia. En: Revista de Educación, 339.

Catecismo de la Iglesia Católica. (1992). Colombia: Librería Juan Pablo II.

Cavelier, Germán. (1988). Las relaciones entre la Santa Sede y Colombia. Tomo I. Bogotá: Editorial Kelly.

Díez Díez, Fernando. (1980). "Estado, Iglesia y desamortización”. En: Jaramillo Uribe, Jaime (Director). Nueva Historia de Colombia, Tomo 2. Bogotá: Planeta.

Eliade Mircea. (1985). El fenómeno religioso. Madrid: Ediciones Cristiandad.

Eliade, Mircea.(1984). El mito del eterno retorno, retorno arquetipos y repetición. Barcelona: Editorial Planeta -De Agostini S.A.

Fernández R., Carmen, Marín, B. Fermín y Rosado, Martín Delia. (1983). La sociedad del siglo XVIII a través del sermonario. Aproximación a su estudio. Cuadernos de Historia Moderna y Contemporánea, No. 4. En sitio Internet: http://revistas.ucm.es/ghi/02110849/articulos/CHMC8383110035A.PDF

García, Francisco. (2005). Una aproximación a la historia de la retórica. En: Icono 14, Revista de comunicación y nuevas tecnologías No. 5. En sitio Internet Consultado en: Septiembre 20 de 2009: www.icono14.net/revista

Gómez Hoyos, Rafael. (1960). "La Iglesia Granadina y la Santa Sede ante la revolución de la Independencia". En: Grito de Independencia en Colombia. Bogotá: Ediciones Académicas Rafael Montoya y Montoya.

Groot, José Manuel. (1953). Historia eclesiástica y civil de Nueva Granada. Bogotá: Biblioteca de autores colombianos III, Editorial ABC. Bogotá.

Jaramillo Roberto. (1946). El clero en la Independencia. Medellín: Ediciones de la Revista Universidad de Antioquia.

La Biblia para el pueblo de Dios. (2008). Bogotá: Sociedad Bíblica Católica Internacional. 
Martínez, Rosa María. (1992). La Iglesia católica en la América IndependienteSiglo XIX. Madrid: Editorial Mapfre.

Sáez, Ricardo. (2002). Preludio al sermón. Criticón. Universidad de Rennes 2. 2002. Pp. 46-61. En sitió Internet Consultado en: Octubre 2 de 2009: http//cvc.cervantes.es/iteratura/criticón/PDF/084-085/084-085_047.pdf

Tisne's Roberto. (1971). "Historia Eclesiástica". En: Historia Extensa de Colombia. Volumen XIII. Tomo 4. Bogotá: Academia Colombiana de Historia.

Tormo Leandro y Gonzalbo, Pilar. (1960). La Historia de la Iglesia en América Latina. Madrid: FERES.

Toro, Iván Darío. Clero insurgente y clero realista en la Revolución colombiana de la Independencia. En sitio Internet: http://dialnet.unirioja.es/servlet/dcfichero articulo?codigo=2592937\&orden $=0$

Varios autores. (1960). Grito de Independencia en Colombia. Bogotá: Ediciones Académicas Rafael Montoya y Montoya.

Velásquez, Erika María. (2006). "La religión católica en las constituciones neogranadinas de 1811 a 1815". En: Revista Facultad de Derecho y Ciencias Políticas. Vol. 36, No. 105. pp.. 283 - 298. En sitio Internet Consultado en: Noviembre

2009:

http://dialnet.unirioja.es/servlet/articulo?codigo $=2367440$

Recibido: 23 de mayo de 2010

Aprobado: 18 de noviembre de 2010 